\title{
Novel Photovoltaic Hot-spotting Fault Detection Algorithm
}

\author{
Mahmoud Dhimish, Member, IEEE, Peter Mather, and Violeta Holmes Member, IEEE
}

\begin{abstract}
In this paper, a novel Photovoltaic (PV) hotspotting fault detection algorithm is presented. The algorithm is implemented using the analysis of 2580 polycrystalline silicon PV modules distributed across the UK. The evaluation of the hot-spots is analysed based on the cumulative density function (CDF) modelling technique, whereas the percentage of power loss (PPL) and PV degradation rate are used to categories the hotspots into eight different categories. Next, the implemented CDF models are used to predict possible PV hot-spots affecting the PV modules. The developed algorithm is evaluated using three different PV modules affected by three different hot-spots. Remarkably, the proposed CDF models precisely categorize the PV hotspots with high-rate of accuracy almost above $80 \%$.
\end{abstract}

Index Terms-Photovoltaic; Solar Energy; Hot-Spots; CDF Modelling; Power Loss, Performance Ratio.

\section{INTRODUCTION}

$\mathrm{H}$ OT-SPOTTING is a reliability problem in Photovoltaic (PV) modules, this phenomena is well-identified when a mismatched solar cell heats up significantly and reduces the PV module output power [1]. PV hot-spots occur when a cell, or group of cells activates at reverse-bias, dissipating power instead of delivering it, and consequently operating at anomalous elevated temperature levels [2] and [3]. The hotspots are also the main cause of PV ageing, and sometimes irreversible damage of entire PV panels [4].

There are a number of other reliability issues affecting PV modules such as PV module disconnection [5], faults associated with maximum power point tracking (MPPT) units [6] and [7], PV micro cracks [8], and fluctuations in the wind speed and humidity variations [9]. All of these factors affect the PV module output power performance, thus decrease its annual energy production. However, this article addresses the impact of hot-spotting in PV modules.

PV Hot-spots can easily be detected using infrared (IR) inspection, which has become a common practice in current PV application as presented in [10]. However, the impact of hot-spots on the operation and performance of PV modules have been not often addressed, which helps us to explain why there is lake of accepted approaches which deal with hotspotting as well as specific criterion referring to the acceptance or rejection of affected PV module in commercial frameworks.

In the past, and still a present practice, hot-spotting effects were usually mitigated by the adoption of bypass diodes which are parallelized with the PV modules, with the target to limit the maximum reverse voltage across the hot-spotted or shaded solar cells, therefore to increase the overall short circuit current and the open circuit voltage [11] - [13]. However, this method of mitigating hot-spots are not encountered the favor, since it requires additional cost and can be even detrimental in terms of power dissipation caused by additional bypass diodes as discussed by Manganiello et al. [14].

Most recently, a distributive MPPT method suggested by Coppola et al. [15] and Olalla et al. [16] is a conventional method to mitigate hot-spots in PV modules, yielded an approximate reduction up to $20{ }^{\circ} \mathrm{C}$ for small and medium hotspotting areas. On the other hand, Kim and Krein [17] show the "inadequateness" of the standard bypass diodes, by the insertion of a series-connected switch are suited to interrupt the current flow during bypass activation process. However, this solution requires a quite complex electronic board design that needs devised power supply and appropriate control logic for activating the hot spot protection device.

In 2018, two hot-spot mitigation techniques developed by Dhimish et al. [18]. Based on MOSFETs connected to the PV module in order to switch ON/OFF the hot-spotted PV solar string. The proposed techniques are proved reliable, but do not contain any modelling or statistical analysis for the overall impact of PV hot-spots on the output power performance.

The main motivation of this work, firstly, to study and analyse the impact of hot-spots on the performance of PV modules. The analysis not only considers local PV modules at specific geographical area, but also wide range of PV modules distributed across the UK; with subtotal of 2580 examined PV modules. This will ensure that the analysis is based on PV modules affected by various environmental conditions such as fluctuations in the wind, irradiance, temperature, and humidity levels. Secondly, propose a suitable modelling technique based on CDF function in order to differentiate the hot-spots into various categories. Finally, use the proposed CDF models to predict the type of the hot-spot affecting the PV modules.

As far as the authors are concerned, there is no probabilistic or statistical analysis models describe the impact of the hotspots on the performance of PV modules based on large scale PV datasets (i.e. $>2500$ hot-spotted PV modules data). 


\section{Methodology}

\section{A. Examined PV modules}

The distributed PV installations data were collected via Solar UK database system, which has the PV modules and strings output voltage, current, and power.

The geographical map presenting the distribution of the PV installations across the UK (only in England, Wales, and Scotland) are shown in Fig. 1. The total inspected PV modules within all examined PV installations are equal to 8340, with the PV technology being Polycrystalline Silicon (Poly-Si).

The majority of the PV modules were installed in 2007, the PV modules were supplied by a combination of homeowners and commercial scale PV installations between 1.1 and 50 $\mathrm{kWp}$ with a wide range of orientation and tilt angles.

The collection of the data was taken from various PV companies. The examined PV systems have a current-voltage $(\mathrm{I}-\mathrm{V})$ and power-voltage $(\mathrm{P}-\mathrm{V})$ curve tracer fitted with the maximum power point tracking (MPPT) units. These instruments are subject to different errors and tolerance rates. Therefore, the data collected from the PV systems were subjected to demanding checks and validation in order to remove and isolate as much inaccurate data as possible. The standard set of filters employed prior to data analysis and investigation stage are as follows:

- The PV modules I-V and P-V curves were captured during clear-sky, non-shading conditions as reported in the database.

- Take into account only PV modules within the UK, since the database contains multiple PV systems installed in wide range of European countries.

- Use only systems with a tilt angle from $30^{\circ}$ to $60^{\circ}$, and orientation between $-30^{\circ}$ to $+30^{\circ}$.

- Use only PV systems with accessible PV modules data, thus it is possible to compare between hotspotted and adjacent free hot-spotted PV modules.

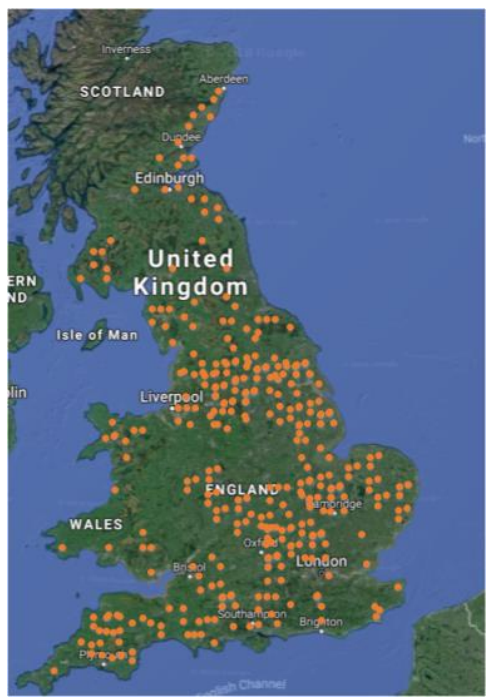

Fig. 1. Geographical map for the PV sites locations used in the analysis
After the interpretation of the selective requirements have been carried out, $6159 \mathrm{PV}$ modules remain (out of 8340). The PV modules is shown in Fig. 2. The number of PV modules which did not contain hot-spots is equal to 3579 , which presents 58\% of the total inspected PV modules. Whereas the probability of the total PV modules contains hot-spotted PV cells are equal to $42 \%$.

The analysis of the hot-spots was analyzed based on the number of hot-spotted PV solar cells in the observed PV modules, despite its location in the same or different PV string. Based upon the available datasets, the hot-spotted PV solar cells were categorized into five groups, it was found that total PV modules affected by each category is equal to:

- 1 hot-spotted solar cell in a PV module: 1058

- 2 hot-spotted solar cells in a PV module: 491

- 3 hot-spotted solar cells in a PV module: 542

- 4 hot-spotted solar cell in a PV module: 283

- $\quad \geq 5$ hot-spotted solar cell in a PV module: 155

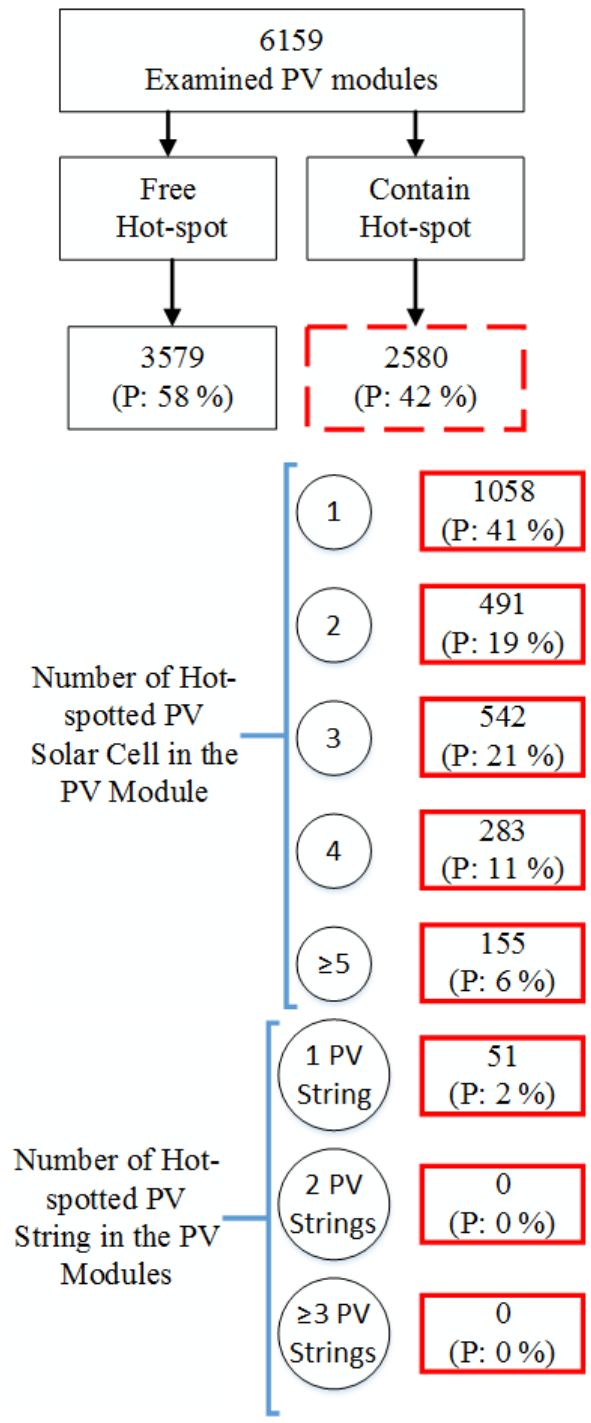

Fig. 2. Hot-spots probability of occurrence among all tested PV modules 


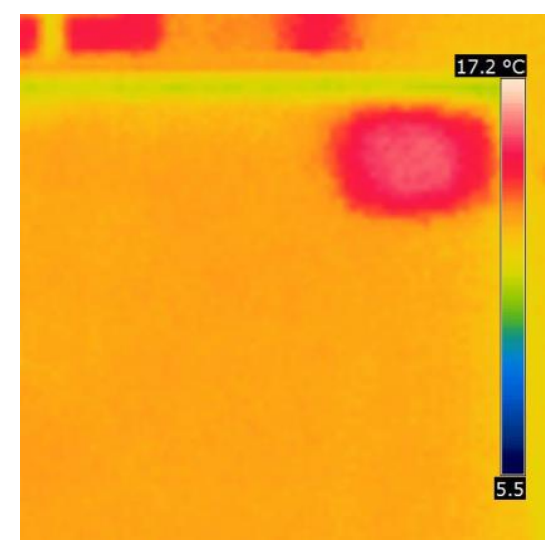

(a)

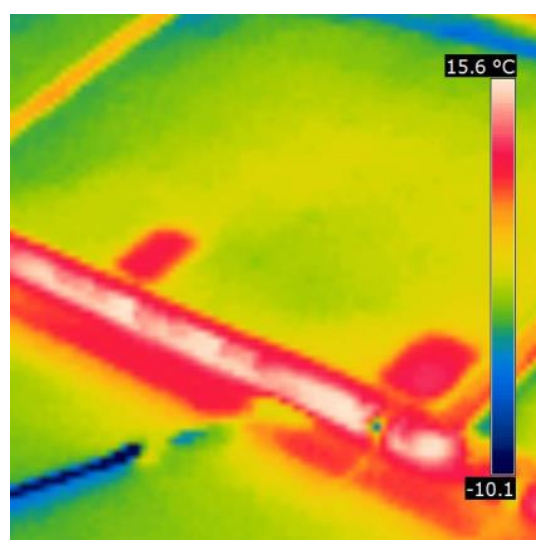

(b)

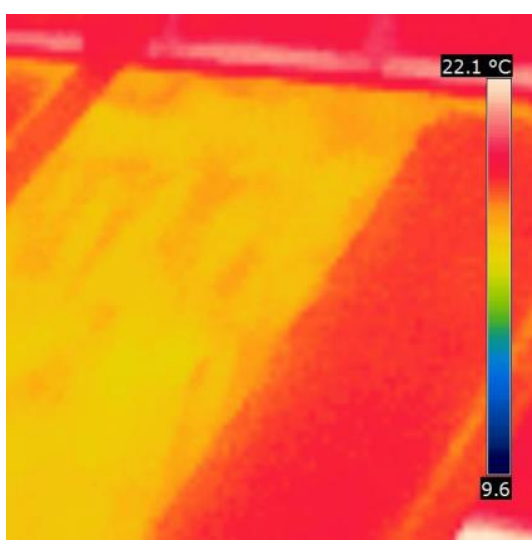

(c)

Fig. 3. Examples for three different types of hot-spots affecting PV modules. (a) One hot-spot, (b) Two hot-spots, (c) Hot-spotted PV string

Furthermore, it was found that fifty-one PV modules out of 2580 contain one hot-spotted PV string. Interestingly, none of the PV modules had two or more hot-spotted PV strings.

Fig. 3 shows an example of three different hot-spots categories, which were identified using a FLIR thermal imaging camera [19]. Fig. 3(a) shows two solar cell affected by a hot-spot, whereas Figs. 3(b) and 3(c) present multiple $(>5)$ hot-spotted solar cells, and one hot-spotted PV string in a PV module respectively.

In order to draw relevant outcomes and novel conclusions, each of the inspected category was modelled independently and it is worth noting that the hot-spots analysis is based on their counts not locations. In addition, faulty conditions such as open or short bypass diodes, disconnection of PV modules in a string, and line-to-line or line-to-ground faults have not been considered in the analysis process of the PV hot-spots.

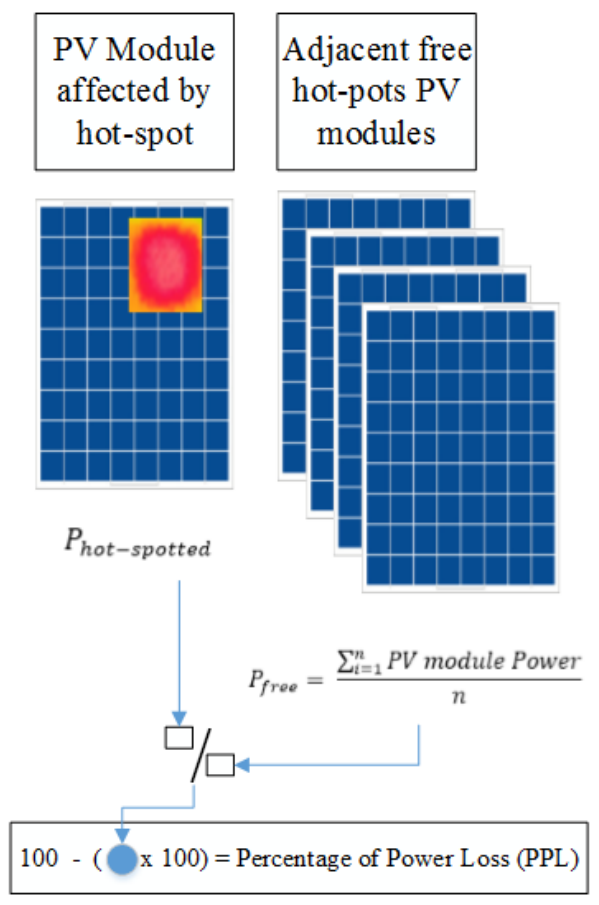

Fig. 4. Percentage of power loss (PPL) estimation for hot-spotted and free hot-spotted PV modules

\section{B. Percentage of Power Loss (PPL) technique}

In order to investigate the power losses in the PV modules affected by hot-spots, and since the PV modules have different output peak power, the percentage of power loss (PPL) technique was used.

Initially, the output power from the PV module affected by hot-spots $\left(P_{\text {hot-spotted }}\right)$ is measured, and then divided by the average output power from adjacent free hot-spotted PV modules. The adjacent average power is calculated using (1). Fig. 4 briefly explains the assessment of the PPL technique.

The calculations of the PPL including the measured and theoretical voltage and current are corrected for 1-Sun conditions (solar irradiance $=1000 \mathrm{~W} / \mathrm{m}^{2}$ ).

$$
P_{\text {free }}=\frac{\sum_{i=1}^{n} P V \text { module Power }}{n}
$$

\section{REsults}

\section{A. Percentage of Power Loss (PPL)}

The evaluation of the data driven by the observed hot-spots and the distribution over histogram profiles are shown in Fig. 5. The histograms contain the PPL values for all the defined categories of the hot-spotted PV modules, as well as the frequency of the PPL at certain levels.

According to Fig. 5, it is evident that the PV modules affected by one hot-spotted solar cell have the least drop in the PPL as shown in Fig. 5(a), the average of the PPL is equal to $0.95 \%$ over a sample size of 1058 PV modules.

The increase in the number of hot-spotted solar cell would increase the percentage of the power loss; for example, Fig. 5(b) shows that the average PPL is equal to $2.0 \%$ for PV modules affected by two hot-spotted solar cells. These results are evaluated over a sample size of 491 PV modules.

The rest of the observed percentage of the power loss for all other hot-spots categories are summarized follows:

- Three hot-spots in a PV module is equal to $2.7 \%$

- Four hot-spots in a PV module is equal to $4.0 \%$

- $\quad \geq 5$ hot-spots in a PV module is equal to $11 \%$

- One PV string in a PV module is equal to $19 \%$ 


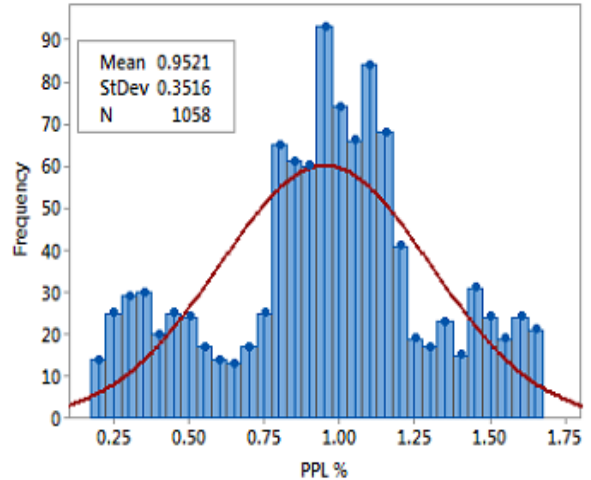

(a)

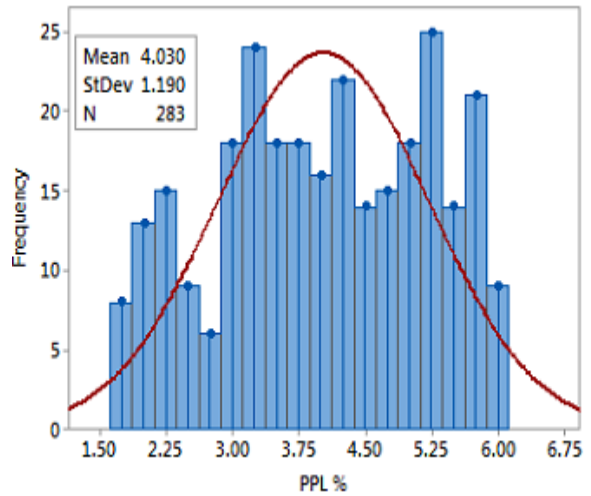

(d)

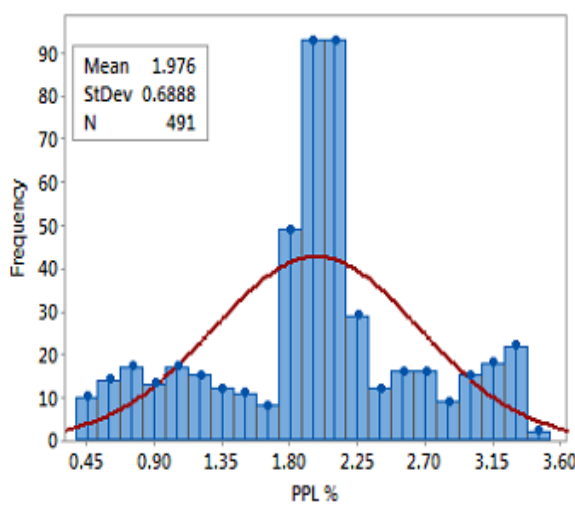

(b)

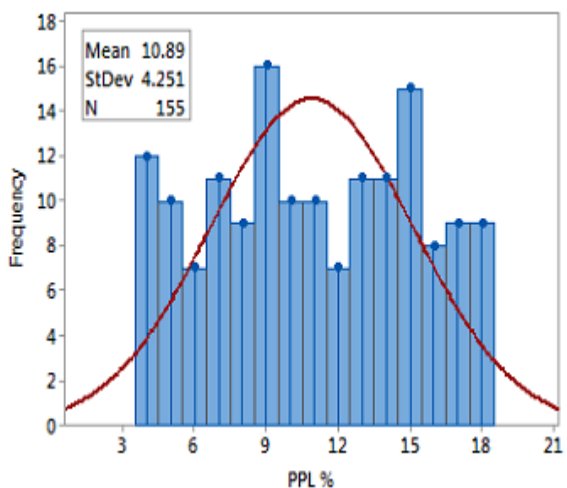

(e)

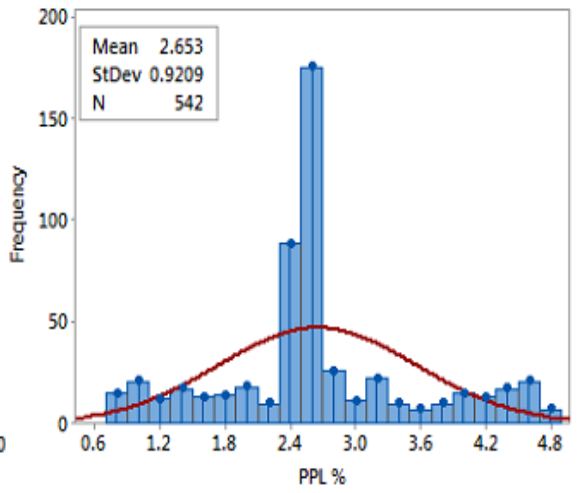

(c)

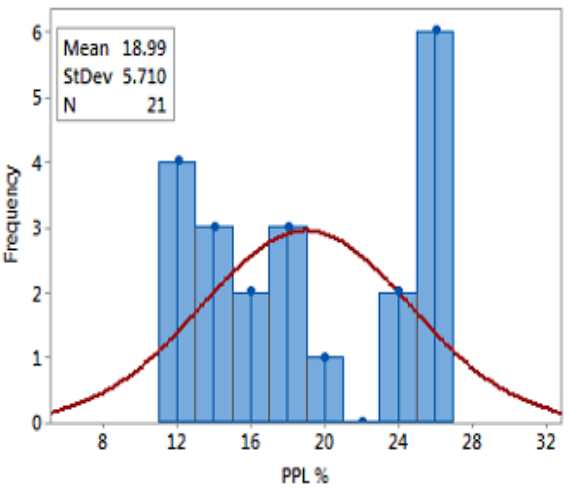

(f)

Fig. 5. Histogram for the PPL vs. frequency of the samples. (a) 1 hot-spotted solar cell, (b) 2 hot-spotted solar cells, (c) 3 hot-spotted solar cells, (d) 4 hotspotted solar cells, (e) $\geq 5$ hot-spotted solar cells, (f) Hot-spotted PV string in a PV module

Interestingly, whilst increasing the hot-spots in PV modules, it is more likely to have greater drop in its output peak power. On the other hand, the PV modules with a complete hot-spotted PV string is caused due to faulty bypass diodes. Therefore, there is more chance to have less output power produced by these particular PV modules, since bypass diodes overcome the issue of the partial shading conditions which normally PV modules suffer from.

In addition, it is worth remembering that all data presented in Fig. 5 are subject to various errors such as the PV system sensors accuracy rate, data collection accuracy, and some other environmental factors, in which the data collected from the observed PV modules were subjected to demanding checks and validation in order to remove and isolate as much inaccurate data as possible.

Furthermore, the data shown in Fig. 5 could be used to implement a relevant theoretical models in order to predict the hot-spots in other PV modules, particularly not incorporated in the data processing. Thus, it is ideally conceivable to inspect PV modules and predict the number of hot-spotted solar cells. This feature has been implemented using the cumulative density function (CDF) modelling technique [20] and [21], which will be describe next.

The provision of probabilistic and error analysis projections is the major improvements which many researchers worldwide relies on to extensively prove/disapprove the chance of an action to accrue [22].

According to previously discussed data shown in Fig. 5, the PPL for PV modules affected by 1, 2, 3, and 4 hot-spotted solar cells are relatively equivalent, where the average PPL varies between $1.0 \%$ and $4.0 \%$. However, the PPL for the PV modules affected by either $\geq 5$ hot-spotted solar cells or one hot-spotted PV string almost between 5.0\% and 30\%. In that case, we have alienated the CDF modelling into two main profiles, principally shown in Fig. 6, where $x$-axis presents the PPL and the percentage of occurrence corresponds to $y$-axis.

CDF plots for the PV modules affected by 1 to 4 hotspotted solar cells are shown in Fig. 6(a). As an example, the first line (blue) is the CDF model for the PV modules affected by 1 hot-spotted solar cell. $90 \%$ of the examined PV modules have a percentage of power loss below $1.4 \%$, where as $10 \%$ is below $0.5 \%$. Therefore, the CDF models present the percentage of the PV modules affected by various hot-spot condition.

According to Fig. 6(a), $10 \%$ and $90 \%$ of the total observed PV modules have a percentage of power loss equals to the following:

- PPL threshold for one hot-spot: $0.5-1.4 \%$

- PPL threshold for two hot-spots: $1.1-2.9 \%$

- PPL threshold for three hot-spots: $1.5-3.8 \%$

- PPL threshold for four hot-spots: $2.5-5.6 \%$

Furthermore, the CDF plots for the PV modules affected by either $\geq 5$ hot-spotted solar cells or one hot-spotted PV string are shown in Fig. 6(b). This figure shows that the PPL thresholds between $10 \%$ and $90 \%$ are equal to:

- $\quad \geq 5$ hot-spots in a PV module: $5.4-16.3 \%$

- $\quad$ One PV string in a PV module: $11.7-26.3 \%$ 


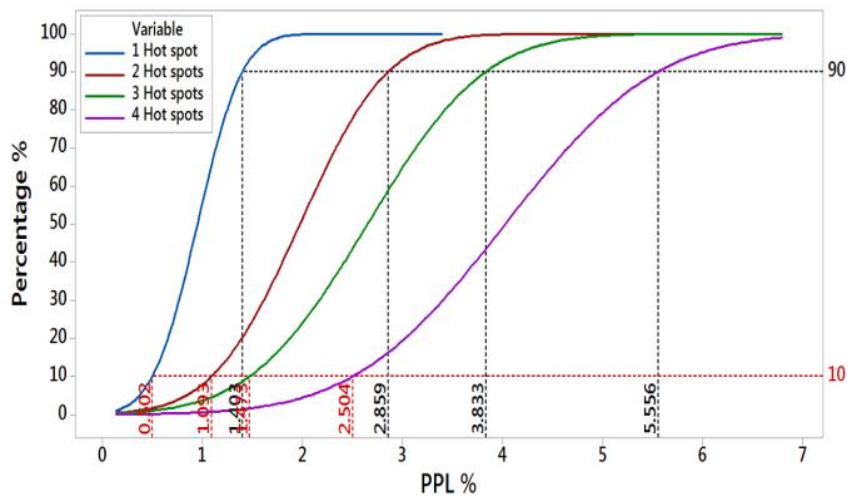

(a)

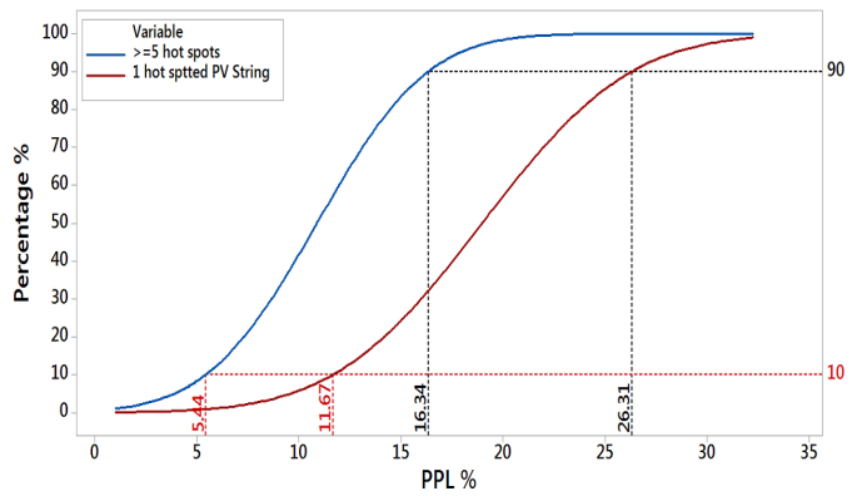

(b)

Fig. 6. Cumulative density function models. (a) CDF model for PV modules affected by 1 to 4 hot-spotted solar cells operated at their first 0 to 10 years, (b) CDF model for PV modules affected by either $\geq 5$ hotspotted solar cells or one hot-spotted PV string in a PV module operated at their first 0 to 10 years

\section{B. Percentage of Power Loss (PPL) with respect to time}

In the previous section, the analysis of the PPL are based on the collected data over 10 years of PV exposure (2007 to 2017). Due to the degradation rate mechanism affecting PV modules, the projection of the CDF plots would be inaccurate in the coming 10 or 20 years. Therefore, the annual degradation rate of the PV modules must be incorporated with the CDF plots.

Based on the analysis done by J. Taylor et al [23], it was found that the average annual degradation rate of $7000 \mathrm{PV}$ modules in the UK is equal to $-0.8 \% / y e a r$. Therefore, we have used this rate to reintroduce the CDF plots for the next 10 years or 20 years of the PV exposure, hence the plots shown in Figs. 7(a-b) must be used with PV modules exposed from 11 to 20 years of operation, Figs. 7(c-d) are used for PV modules operated from 21 to 30 years, whereas Fig. 6(a-b) are for PV modules operated at their first 10 years (0 to 10 years) of solar exposure.

Figs. 7(a-b) show the output results of CDF plot for the PPL for all hot-spotting categories. These results are obtained using the degradation rate of $-0.8 \%$ /year over a period of nine years. For comparison purposes, it is shown that four hot-spotted solar cells would have a PPL of $2.7 \%$ to $6.0 \%$ from 11 to 20 years of PV operation, while PPL was predicted from $2.5 \%$ to $5.6 \%$ in the first 10 years as shown in Fig. 6(a).

Figs. 7(c-d) presents the output results of the CDF plot for the PPL analysis for all hot-spotting categories including PV modules at their 21 to 30 operation. The used degradation rate is equal to $-0.8 \%$ year as suggested by [23].

A brief comparison for all obtained PPL thresholds are shown in Table I. It is evident that the loss in the power threshold increase while the PV age increase, these thresholds will be used in the next section to evaluate the appropriateness of the proposed methodology using various PV modules affected by different types of hot-spots.

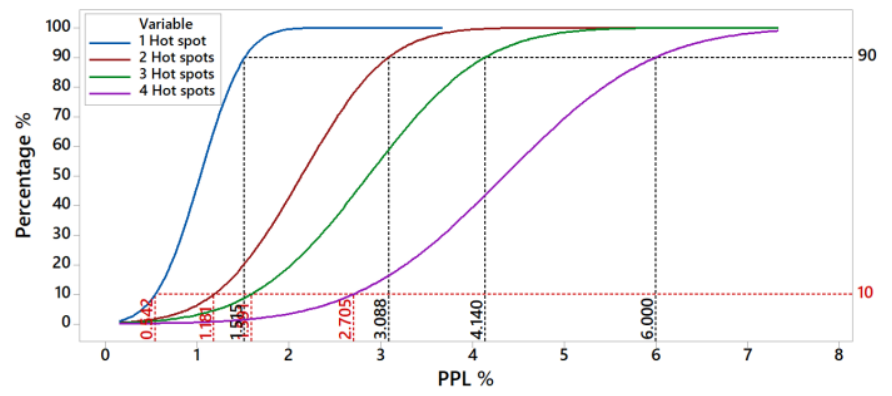

(a)

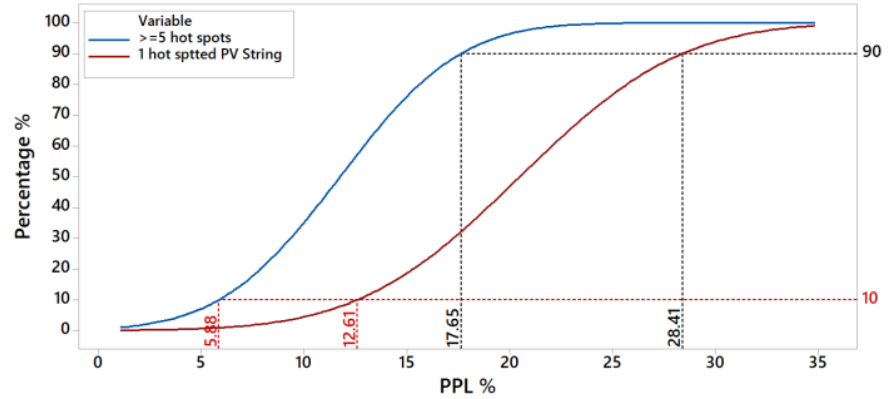

(b)

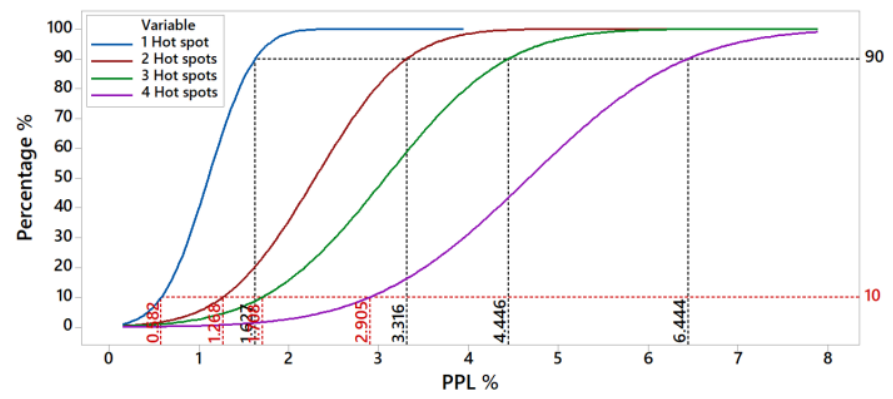

(c)

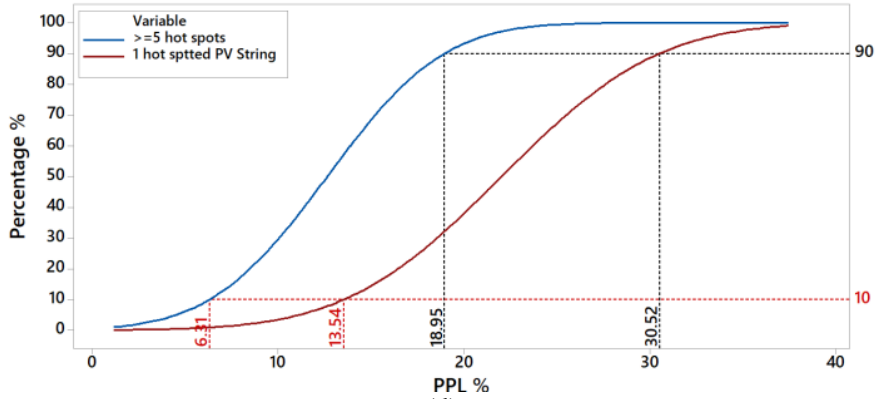

(d)

Fig. 7. Cumulative density function models. (a) CDF model for PV modules affected by 1 to 4 hot-spotted solar cells and operated at their 11 to 20 years, (b) CDF model for PV modules affected by either $\geq 5$ hot-spotted solar cells or one hot-spotted PV string in a PV module and operated at their 11 to 20 years, (a) CDF model for PV modules affected by 1 to 4 hot-spotted solar cells and operated at their 21 to 30 years, (b) CDF model for PV modules affected by either $\geq 5$ hot-spotted solar cells or one hot-spotted PV string in a PV module and operated at their 21 to 30 years 
Table I Summary of the CDF predictions (10\% and 90\%) for the PPL of the inspected hot-spots

\begin{tabular}{|c|c|c|c|c|c|c|}
\hline \multirow[t]{2}{*}{ PV Hot-spotting Type } & \multicolumn{2}{|c|}{ CDF predictions from 0 to 10 years } & \multicolumn{2}{|c|}{ CDF predictions from 11 to 20 years } & \multicolumn{2}{|c|}{ CDF predictions from 21 to 30 years } \\
\hline & $10 \%$ PLL & $90 \%$ PLL & $10 \%$ PLL & $90 \%$ PLL & $10 \%$ PLL & $90 \%$ PLL \\
\hline 1 hot-spotted solar cell & 0.5 & 1.5 & 0.5 & 1.5 & 0.6 & 1.6 \\
\hline 2 hot-spotted solar cells & 1.1 & 2.9 & 1.2 & 3.0 & 1.3 & 3.3 \\
\hline 3 hot-spotted solar cells & 1.5 & 3.8 & 1.6 & 4.1 & 1.7 & 4.4 \\
\hline 4 hot-spotted solar cells & 2.5 & 5.6 & 2.7 & 6.0 & 2.9 & 6.4 \\
\hline$\geq 5$ hot-spotted solar cells & 5.4 & 16.3 & 5.9 & 17.7 & 6.3 & 19.0 \\
\hline 1 hot-spotted PV string & 11.7 & 26.3 & 12.6 & 28.4 & 13.5 & 30.5 \\
\hline
\end{tabular}

\section{Evaluation}

In this section, the appropriateness and accuracy of the CDF models will be evaluated using various hot-spots types inspected on the PV system shown in Fig. 8(a), the PV system age of installation is less than 10 years; installed in 2014. The data of this PV system is not part of the observation monitored and discussed earlier in the methodology section. The PV modules' main electrical characteristics including, maximum power point $220 \mathrm{~W}$, voltage at maximum power point $28.7 \mathrm{~V}$, and current at maximum power point $7.67 \mathrm{~A}$.

The evaluation process is principally divided into three steps. At first, the Power-Voltage (P-V) curve of the selected PV module will be measured, hence to estimate the percentage of power loss (PPL) compared to healthy/non-hot-spotted PV modules performance; results are shown in Fig. 8(b). Next, the PPL will be integrated into the CDF models taken from Fig. 6 since the examined PV module are in operation less than 10 years. Finally, to confirm the prediction of the CDF models, the thermal image of the inspected PV module will be taken into account.

Fig. 8(b) shows a healthy vs. hot-spotted PV module P-V

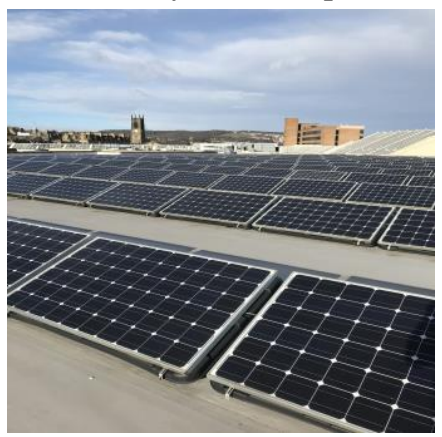

(a)

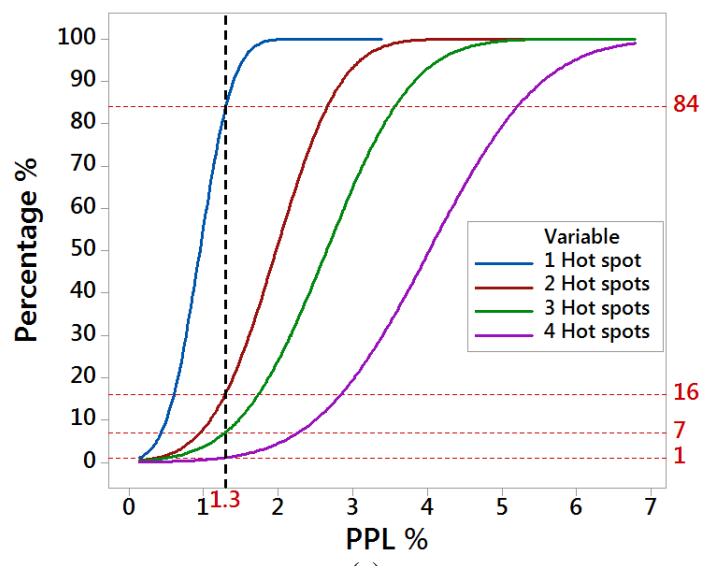

(c) curve measured at standard test conditions (STC), where the Irradiance is equal to $1000 \mathrm{~W} / \mathrm{m}^{2}$ and ambient temperature is $25^{\circ} \mathrm{C}$. It is evident that healthy PV module generates a peak power of $220 \mathrm{~W}$, whereas the hot-spotted PV module had a peak power of $217.14 \mathrm{~W}$. Resulting a PPL of $1.3 \%$; refer to Fig. 4 for calculating the PPL percentage.

Next, this PPL percentage has been incorporated into the CDF model as shown in Fig. 8(c). This percentage of the power loss correlates almost with all the CDF profiles, and according to this interception, there is $84 \%$ chance that the inspected PV module is affected by only one hot-spotted solar cell. Furthermore, there is $16 \%$ and $7 \%$ chance that the PV module is affected by two or three hot-spotted solar cells, respectively. Finally, there is only $1 \%$ chance that the PV module is affected by four hot-spotted solar cells.

Therefore, according to the CDF models result, we would expect that the examined PV module is affected by one hotspotted solar cell. In order to judge whether this prediction is correct or incorrect, a thermal image of the PV module has been captured. Remarkably and as shown in Fig. 8(d), the inspected PV module is only affected by one hot-spotted solar cell located at the bottom of the PV module.

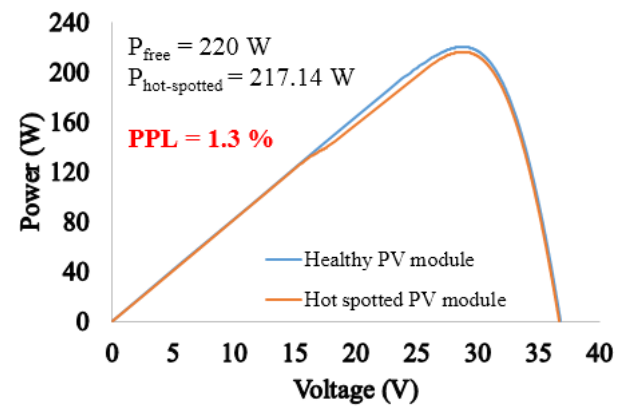

(b)

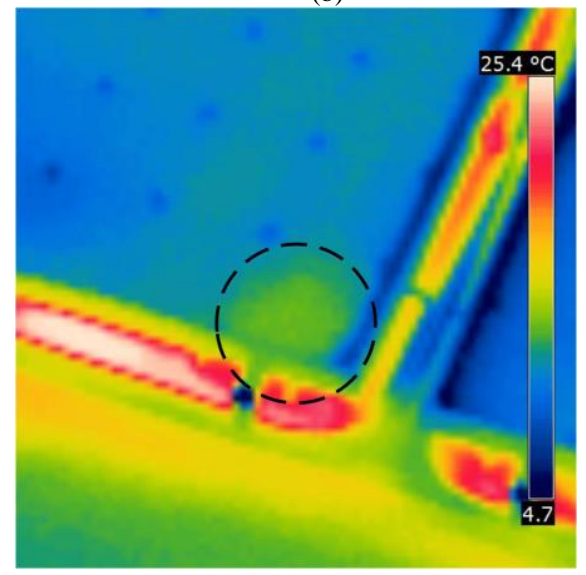

(d)

Fig. 8. (a) Examined PV modules, (b) Power-Voltage curves for healthy and the inspected PV module, (c) CDF plot at PPL 1.3\%, (d) Thermal image of the inspected PV module 
Therefore, this result confirms the ability of the proposed technique using the CDF models in predicting possible hotspots in PV modules, and also it confirms the appropriate use of the PPL as an indicator for the implementation of the CDF models.

In fact, it is worthy noticing that the CDF models and its evaluation process depends on the inspection process, hence it is required to measure the $\mathrm{P}-\mathrm{V}$ curve in order to calculate the PPL. Another limitation associated with the proposed technique that its requirement of the visual inspection for the $\mathrm{PV}$ modules, this is to ensure that there are no faults such as partial shading, cell cracking, glass breakage, and excessive

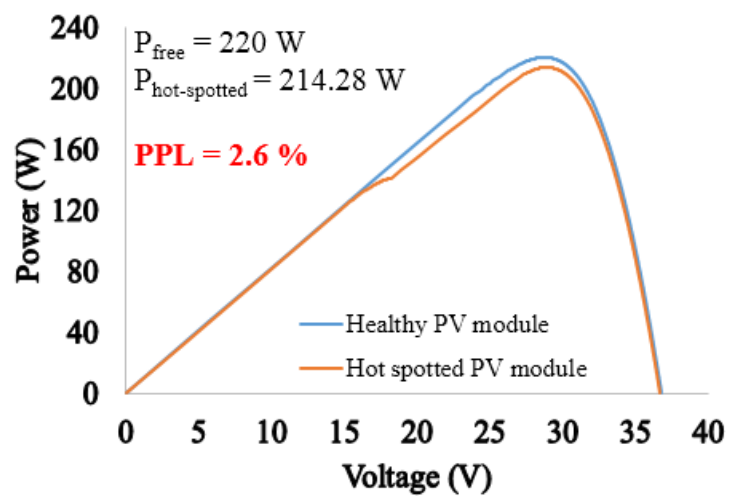

(a)

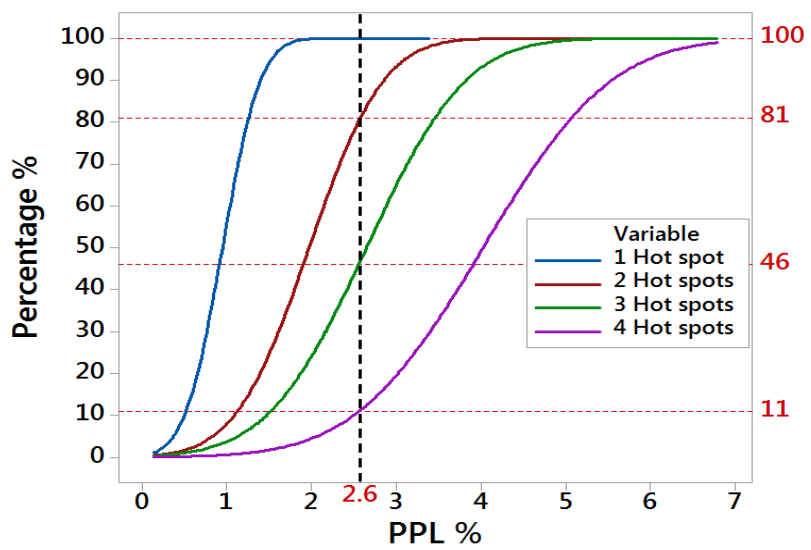

(b)

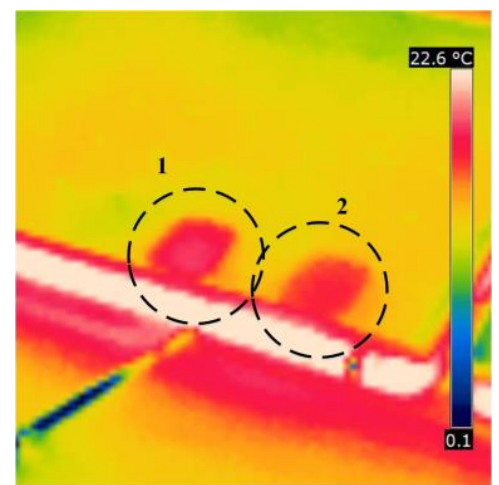

(c)

Fig. 9. Evaluating the proposed CDF model using a PV module affected by two hot-spotted solar cells. (a) Measured P-V curve, (b) CDF model interception with PPL, (c) Thermography image of the inspected PV module soling affecting the inspected PV module.

Similarly, the CDF models are evaluated using different hot-spot categories. Fig. 9(a) shows the P-V curve for a PV module, where the PPL is at $2.6 \%$. According to the CDF profiles shown in Fig 9(b), the prediction of the hot-spot type is as follows:

- 1 hot-spot: $100 \%$

- 2 hot-spots: $81 \%$

- 3 hot-spots: $46 \%$

- 4 hot-spots: $11 \%$

As a result, the first option which states that there is $100 \%$ chance that the PV module is affected by one hot-spotted cell is relatively unrealistic, since this rate of occurrence is at the saturation level of the CDF plot, and as described earlier, at this level the CDF model would not be decisive in the prediction process because the saturation limit keeps at $100 \%$ for almost the rest of the CDF profile. Therefore, this level (saturation) is predominantly neglected [24].

Accordingly, we would expect that the inspected PV module is affected by two hot-spots, with chance of occurrence $81 \%$. In fact, this results are equitable, since by looking to the thermal image of the PV module shown in Fig. 9(c), the PV is evidently affected by two hot-spotted solar cells, which confirms the results of the CDF models.

Subsequently, Fig. 10(a) shows the P-V curve for another inspected PV module. There is large drop in the PPL of about $15.7 \%$, where the peak power of the inspected PV module is equal to $185.46 \mathrm{~W}$. Hence, the second CDF model shown in Fig. 6(b) will be used to predict the PV module hot-spot, since the CDF plot used in either Fig. 6(a) or Figs. 8 and 9 have 7\% limit for the PPL.

Fig. 10(b) shows that there is $87 \%$ chance that the PV module is affected by $\geq 5$ hot-spotted solar cells. Whereas there is only $28 \%$ chance that the PV module is affected by one hot spotted PV string. Based on the thermal image of the PV module, it is evident that there are almost seven solar cells affected by hot-spots. This result confirms the ability of the CDF model to accurately categories the hot-spotting type.

\section{CONCLUSION}

This paper presents the development of novel PV hotspotting fault detection algorithm using the analysis of 2580 PV modules affected by six different types of hot-spots. The implemented algorithm is based on the analysis of the cumulative density function (CDF) models to precisely predict hot-spots affecting PV modules. In order to differentiate between hot-spotting categories, the developed algorithm uses the analysis of the percentage of the power loss (PPL), and PV degradation rate.

In order to evaluate the appropriateness of the presented algorithm, three different PV modules affected by one, two, and several (>6) hot-spots have been examined. The hot-spots were categorized correctly, where the CDF percentage of prediction is always above $80 \%$, which confirms the ability of the CDF models to precisely categories the hot-spots using simple, reliable, and fast detection approach. 


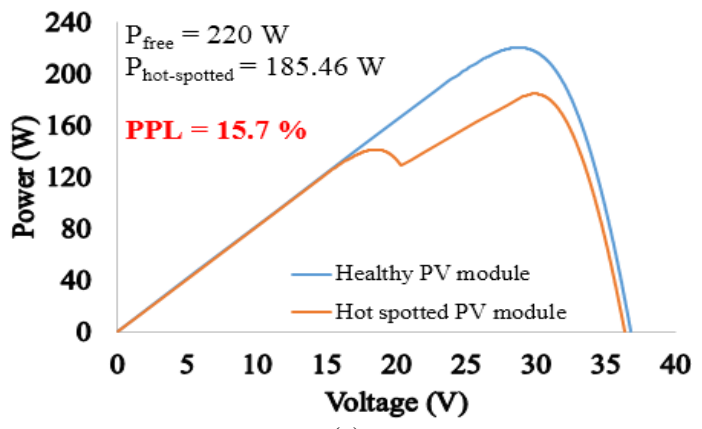

(a)

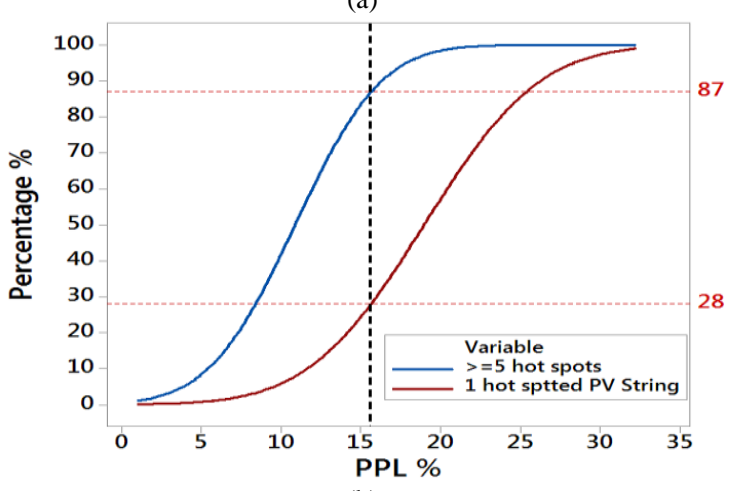

(b)

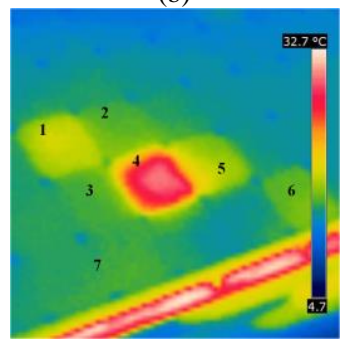

(c)

Fig. 10. Evaluating the proposed CDF model using a PV module affected by several hot-spotted solar cells. (a) Measured P-V curve, (b) CDF model interception with PPL, (c) Thermography image of the inspected PV module

\section{REFERENCES}

[1] T. Ghanbari, "Permanent partial shading detection for protection of photovoltaic panels against hot spotting," in IET Renewable Energy Generation, vol. 11, no. 1, pp. 123-131, 2017, doi: 10.1049/ietrpg.2016.0294.

[2] M. Dhimish, V. Holmes, P. Mather, and M. Sibley, " Novel hot spot mitigation technique to enhance photovoltaic solar panels output power performance," in Solar Energy Materials and Solar Cells, vol. 179, pp. 72-79, June 2018, doi: 10.1016/j.solmat.2018.02.019.

[3] J. Oh et al., "Reduction of PV Module Temperature Using Thermally Conductive Backsheets," in IEEE Journal of Photovoltaics, vol. 8, no. 5, pp. 1160-1167, Sept. 2018, doi: 10.1109/JPHOTOV.2018.2841511.

[4] M. Simon, and E. L. Meyer, "Detection and analysis of hot-spot formation in solar cells," in Solar Energy Materials and Solar Cells, vol. 94, no. 2, pp. 106-113, 2010, doi: 10.1016/j.solmat.2009.09.016.

[5] J. Bauer, W. Kwapil, M. C. Schubert, W. Warta, K. Bothe and O. Breitenstein, "Comments on the paper "Detection and analysis of hotspot formation in solar cells" published by M. Simon and E.L. Meyer in Solar Energy Materials \& Solar Cells 94 (2010) 106-113," in Solar Energy Materials and Solar Cells, vol. 99, pp. 362-364, 2012, doi: 10.1016/j.solmat.2011.12.014.

[6] T. K. Soon and S. Mekhilef, "A Fast-Converging MPPT Technique for Photovoltaic System Under Fast-Varying Solar Irradiation and Load Resistance," in IEEE Transactions on Industrial Informatics, vol. 11, no. 1, pp. 176-186, Feb. 2015, doi: 10.1109/TII.2014.2378231.

[7] Z. Yi and A. H. Etemadi, "Fault Detection for Photovoltaic Systems Based on Multi-Resolution Signal Decomposition and Fuzzy Inference
Systems," in IEEE Transactions on Smart Grid, vol. 8, no. 3, pp. 12741283, May 2017, doi: 10.1109/TSG.2016.2587244.

[8] M. Dhimish, V. Holmes, P. Mather, C. Aissa and M. Sibley, "Development of 3D graph-based model to examine photovoltaic micro cracks," in Journal of Science: Advanced Materials and Devices, vol. 3, no. 3, pp. 380-388, 2018, doi: 10.1016/j.jsamd.2018.07.004.

[9] B. Burduhos, I. Vişa, A. Duţă and M. Neagoe, "Analysis of the Conversion Efficiency of Five Types of Photovoltaic Modules During High Relative Humidity Time Periods," in IEEE Journal of Photovoltaics, vol. 8, no. 6, pp. 1716-1724, Nov. 2018, doi: 10.1109/JPHOTOV.2018.2861720.

[10] M. Abdelhamid, R. Singh and M. Omar, "Review of Microcrack Detection Techniques for Silicon Solar Cells," in IEEE Journal of Photovoltaics, vol. 4, no. 1, pp. 514-524, Jan. 2014, doi: 10.1109/JPHOTOV.2013.2285622.

[11] Y. Hung, Y. Cheng, M. Cai, C. Lu and H. Su, "High-Voltage 12.5-V Backside-Illuminated CMOS Photovoltaic Mini-Modules," in IEEE Journal of the Electron Devices Society, vol. 6, pp. 135-138, 2018, doi: 10.1109/JEDS.2017.2785340.

[12] A. Thangavelu, S. Vairakannu and D. Parvathyshankar, "Linear open circuit voltage-variable step-size-incremental conductance strategybased hybrid MPPT controller for remote power applications," in IET Power Electronics, vol. 10, no. 11, pp. 1363-1376, 99 2017, doi: 10.1049/iet-pel.2016.0245.

[13] M. Dhimish, V. Holmes, B. Mehrdadi, M. Dales, and P. Mather, "PV output power enhancement using two mitigation techniques for hot spots and partially shaded solar cells," in Electric Power Systems Research, vol. 158, pp. 15-25, 2018, doi: 10.1016/j.epsr.2018.01.002.

[14] P. Manganiello, M. Balato and M. Vitelli, "A Survey on Mismatching and Aging of PV Modules: The Closed Loop," in IEEE Transactions on Industrial Electronics, vol. 62, no. 11, pp. 7276-7286, Nov. 2015, doi: 10.1109/TIE.2015.2418731.

[15] M. Coppola, S. Daliento, P. Guerriero, D. Lauria and E. Napoli, "On the design and the control of a coupled-inductors boost dc-ac converter for an individual PV panel," International Symposium on Power Electronics Power Electronics, Electrical Drives, Automation and Motion, Sorrento, 2012, pp. 1154-1159, doi: 10.1109/SPEEDAM.2012.6264548.

[16] C. Olalla, Md. Hasan, C. Deline, and D. Maksimovic, "Mitigation of Hot-Spots in Photovoltaic Systems Using Distributed Power Electronics," in Energies, vol. 11, no. 4, pp. 726, 2018, doi: 10.3390/en11040726.

[17] K. A. Kim and P. T. Krein, "Reexamination of Photovoltaic Hot Spotting to Show Inadequacy of the Bypass Diode," in IEEE Journal of Photovoltaics, vol. 5, no. 5, pp. 1435-1441, Sept. 2015, doi: 10.1109/JPHOTOV.2015.2444091.

[18] M. Dhimish, V. Holmes, B. Mehrdadi, M. Dales, and P. Mather, "Output-Power Enhancement for Hot Spotted Polycrystalline Photovoltaic Solar Cells," in IEEE Transactions on Device and Materials Reliability, vol. 18, no. 1, pp. 37-45, March 2018, doi: 10.1109/TDMR.2017.2780224.

[19] W. S. M. Brooks, D. A. Lamb and S. J. C. Irvine, "IR Reflectance Imaging for Crystalline Si Solar Cell Crack Detection," in IEEE Journal of Photovoltaics, vol. 5, no. 5, pp. 1271-1275, Sept. 2015, doi: 10.1109/JPHOTOV.2015.2438636.

[20] J. A. Maya, L. R. Vega and C. G. Galarza, "A Closed-Form Approximation for the CDF of the Sum of Independent Random Variables," in IEEE Signal Processing Letters, vol. 24, no. 1, pp. 121125, Jan. 2017, doi: 10.1109/LSP.2016.2643281.

[21] V. Huayamave, A. Ceballos, C. Barriento, H. Seigneur, S. Barkaszi, E. Divo and A. Kassab, "RBF-trained POD-accelerated CFD analysis of wind loads on PV systems," in International Journal of Numerical Methods for Heat \& Fluid Flow, vol. 27, no. 3, pp. 660-673, 2017, doi: 10.1108/HFF-03-2016-0083 .

[22] S. V. Amari, H. Pham and R. B. Misra, "Reliability Characteristics of \$ k \$-out-of- \$n\$ Warm Standby Systems," in IEEE Transactions on Reliability, vol. 61, no. 4, pp. 1007-1018, Dec. 2012, doi: 10.1109/TR.2012.2220891.

[23] J. Taylor, J. Leloux, L. M. H. Hall, A. M. Everard, J. Briggs and A. Buckley, "Performance of distributed PV in the UK: a statistical analysis of over 7000 systems", in 31 $3{ }^{\text {st }}$ European Photovoltaic Solar Energy Conference and Exhibition, Hamburg, Germany, Sep. 2015.

[24] K. H. Meng, R. Mertens and E. Rosenbaum, "Piecewise-Linear Model With Transient Relaxation for Circuit-Level ESD Simulation," in IEEE Transactions on Device and Materials Reliability, vol. 15, no. 3, pp. 464-466, Sept. 2015, doi: 10.1109/TDMR.2015.2466436. 


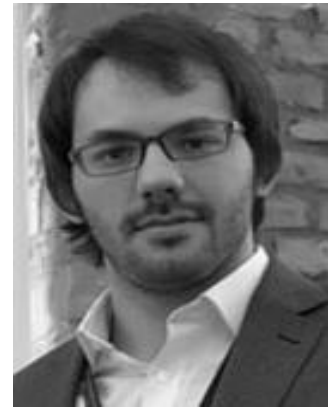

Mahmoud Dhimish (M'16) is Lecturer in Electronics and Control Engineering at the University of Huddersfield, UK. He graduated with M.Sc. in Electronics and Communication Engineering (Distinction) from the University of Huddersfield. Following this he gained a Ph.D. entitled "Fault Detection and Performance Analysis of Photovoltaic Installations" also from the University of Huddersfield. His current research interests include design, control, and performance analysis of photovoltaic systems.

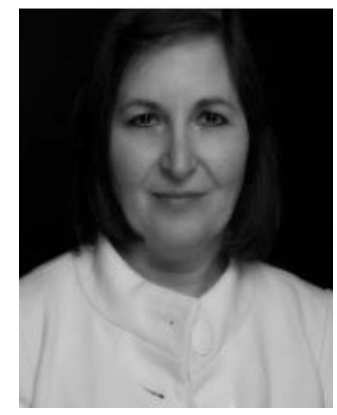

Violeta Holmes (M'18) is a Reader in High Performance Computing at the Huddersfield University with over 25 years of teaching and research experience in computing and engineering. From 2010 to 2018 she was a Subject Leader for Electronic and Electrical Engineering. She also cofounded the HPC Research Group which aims to promote the links between high performance computer users, developers and researchers across various international research groups and institutes.

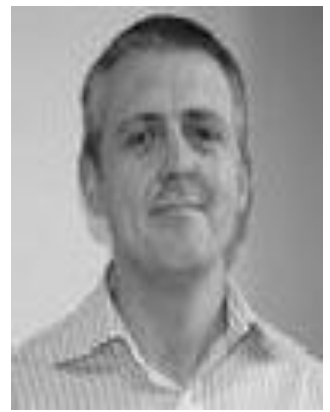

Peter Mather is currently a Senior Lecturer with the School of Computing and Engineering, University of Huddersfield, Huddersfield, U.K. He is the Course Leader for all the M.Eng./B.Eng. and B.Sc. electronics courses. He is currently developing a wide range of electronic and associated systems from Virtual Hardware Description Language (VHDL) to Sigma-Delta Analogue digital conversion testing of mixed signal devices. 